\title{
A Discussion on Current Issues for Semantic Interoperability in an Integrated Manufacturing System
}

\author{
Ramon Martinez PEREIRA, Anderson Luis SZEJKA ${ }^{1}$ and Osiris CANCIGLIERI \\ JUNIOR \\ Industrial and Systems Engineering Graduate Program (PPGEPS), Pontifical Catholic \\ University of Parana (PUCPR), Curitiba, Brazil
}

\begin{abstract}
Digital manufacturing has been challenged by the manufacturing industry to rationalise different ways to connect and to exchange information and knowledge across the manufacturing systems. One of the main pillars of the Industry 4.0 concept is the horizontal and vertical integration with intelligent and self-adaptive systems. For this to be possible, the manufacturing industry applies an extensive range of software tools to aid its activities, such as SCADA, MES, ERP, 3D CAD, $\mathrm{CAM}$, and so on. Individually, each one performs its function to support the manufacturing process. However, these software tools do not have an effective integration and interoperation, since they present different database structures, variables that have the same information with different names and data structures, and closed systems. Thus, it has been identified semantic interoperability issues (misinterpretations and mistakes) in view of the information heterogeneity from multiple perspectives and their relationships across the manufacturing process. In this context, this paper aims to present a discussion of interoperability issues across the manufacturing systems, as well as to introduce possible solutions according to the related works. a holistic approach is critical factors for long-term competitiveness solutions. The literature points out that the solution to this problem may be in the application of semantic technologies. These have the potential to provide solutions that are more comprehensive than the industrial approaches that have been applied through the formalization of information so that knowledge can be shared among multiple domains.
\end{abstract}

Keywords. Manufacturing System, Semantic Interoperability, Formal Models, Semantic Reconciliation.

\section{Introduction}

Nowadays the companies need to answer quickly to the external changes concerning the stakeholder's needs[1]. In order for this to be possible, the manufacturing industry applies a varied range of software tools to support their activities. Some of the main tools are Product Lifecycle Management (PLM), Enterprise Resources Planning (ERP), Supply Chain Management (SCM), Manufacturing Execution Systems (MES), Supervisory Control and Data Acquisition (SCADA), and specific machine control systems [2]. All these systems together sustain the manufacturing process as a whole, from the highest planning level to the shop floor. To guarantee the highest productivity with a lesser

${ }^{1}$ Corresponding author, Mail : anderson.szejka@pucpr.br. 
amount of loss and rework, it is necessary that these systems operate in an integrated manner.

For an integration of systems to exist, these must exchange and share information. These systems share thousands of heterogeneous information and knowledge from multiple groups within and across institutional boundaries [3][4][5]. For example, the wrong identification of an item in a lot of parts with defects could cause the need for a recall in the automotive industry. The lack or low quality of information must generate several types of damages (time, quality, financial loss, and so on).

There is an extensive range of systems available to the companies and each one has its own structure and language since each one was developed by diverse producers. All tools are created and optimized to aid a specific part of the manufacturing system process. In diverse situations there is not a single possibility of integration of the system, causing the extreme dependency on human participation and interpretation of the process. When the integration was predicted, it is usually based on specific patterns, that might not even be shared by the other applications. According to [2] the application of patterns of industrial communication can help, but nowadays these tend to be focused on few domains and are not adequate for the most variated layers of knowledge and information that need to be managed during the manufacturer.

The knowledge from every part of the process and development of the product can be formalized, generating the representation of the same object coming from multiples points of view, as well as different representations of similar concepts [6][7]. [8] defines the multiple representations of an artefact or concept as "semantic heterogeneity", which is an obstacle to the process of manufacture. To solve this problem it is necessary to realize the process denominated "semantic reconciliation". This process s usually realized manually by the programmers on the moment of integrating different systems, or by the machine operators themselves during the manufacturing. In order to realize this process in a more automated environment, the companies are investing in computational network emerging technologies, such as the Semantic Web [11][12][13].

The Semantic Web is, in synthesis, a network of relationships between entities. However it's objective is to operate as a virtual model of the object or process in the way that every part involved in the manufacture, machine or human, can be able to access the requirements of the product and process that is being produced in a common environment. The systematization of the knowledge, denoted interoperability, is one of the main aspects of the Semantic Web and is promoted through the ontological integration, with the goal to create a common ontology to every source of knowledge in an environment of information exchange [14][15][16][17].

An ontology is an explicit and formal specification of the characteristics of a term in a domain, as well as the relationships between these terms [9]. In computational systems, an ontology is a data structure where characteristics of certain entities or environments are stored, as well as the relationships between different characteristics of the same entity or different entities, registered in a machine-readable format. [8][10]

In this context, this article has the objective to discuss the possible application of ontologies to solve the problem of semantic interoperability, present on the information systems, in an integrated manufacturing system to minimize the misinterpretation and to promote the automatic semantic reconciliation between these systems.

Chapter 2 presents a specific view about the integration problem in manufacture aid systems, and where the system based on ontologies could be applied. Chapter 3 presents the main topics that indicate the path to the delimitation of the problem, and possible solutions, according to related works present in the literature. Chapter 4 promotes the 
discussion of a possible solution based in ontologies for the semantic interoperability problem in the integrated manufacturing system.

\section{Problem Statement}

"An ounce of information is worth a pound of data. An ounce of knowledge is worth a pound of information. An ounce of understanding is worth a pound of knowledge" [18]. Figure 1 presents the view of a conceptual integrated manufacturing system model, associated with the levels of content present on the human mind according to [18]. These levels are:

- Data Level - it is composed of symbols that represent the properties of objects and environments. These are raw, and can exist in many forms, usable or not [18]. It's the level where the sensors, transducers, actuators, motors and etc. are present;

- Information Level - it is the level where is present the data that have been given meaning through relational connections [18]. Comprehend the layers of control - composed by PLCs and other controllers - and SCADA / HMI, as well as the layers, corresponding to the systems of corporative management, such as MES and ERP. In this level the data are already refined and have a local practice application, that is, in the process that they are inserted;

- Knowledge Level - it is a collection of information that has the intention to be useful [18] not only for the process in question, but also to the other processes inside the same company, or even other companies. In the integrated manufacturing system, in general, there is no system applied to this level of content;

- Understanding Level - this is the process that makes it possible to create new knowledge through the knowledge obtained early. The difference between knowledge and understanding is the same as memorizing and learning [18]. In this level occurs the decision-making on a company level, where the managers use all of the knowledge generated to parametrize all the processes in the way to direct the whole company to attend to reach the goals planned, as well as planning new goals.

Figure 1 also proposes two distinct levels of integration present on the processes of operation and production in manufacturing:

- Vertical Integration - it is integration between the different layers of systems inside the same manufacturing process;

- Horizontal Integration - it is the integration among the distinct processes that compose the integrated manufacturing system. 


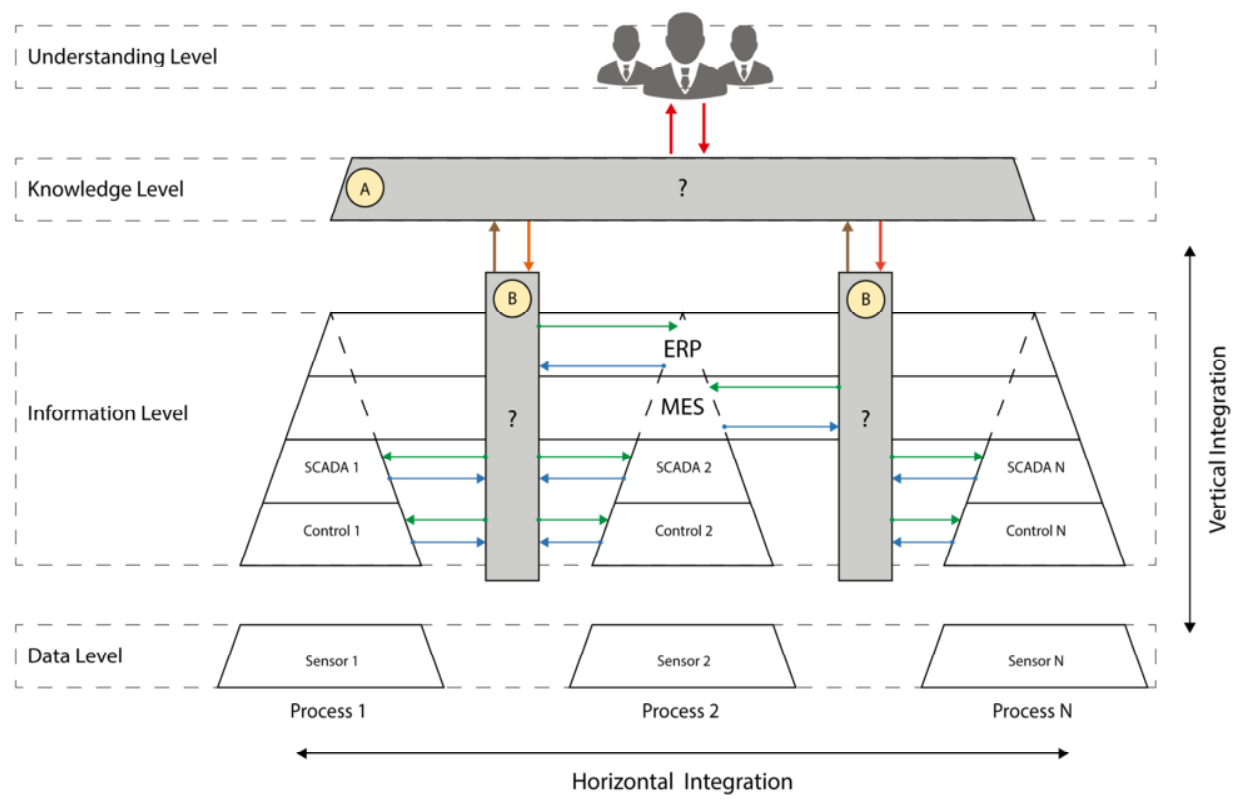

Figure 1. Elements of a Conceptual Integrated Manufacturing System.

Figure 1 shows ideal conditions, where all the systems operate together and information traffics in all the ways. However, this doesn't happen in reality [3]. The actual manufacturing systems have some kind of integration, but this is based mostly on industrial protocols, and they can reach more than two layers of information. [19] mentions that although industry has responded to the interoperability challenges with collaboration interfaces and integration mechanisms, these approaches may become unsustainable with the huge variety of system architectures in development.

In detail A of Figure 1, it is possible to verify that there is no specific system to aid the level of knowledge, that is, applying the information captured from the processes. This happens because the functions of these levels are completely attributed to the managers and operators, once that the actual systems, in general, does not have any automation or intelligence created to aid this process.

In order to create a tool for the automation of the knowledge level, it is necessary that all the information and knowledge originating from the process to be available. The detail B of Figure 1 points the need for an element in the system to unify all the knowledge and information coming from the most diverse layers of the integrated manufacturing system. Yet, in this process, two problems may appear: I - the same information \variable being applied to different components (semantic problem) and II - different variables \ information being applied to the same component (syntactic problem) [20]. These problems are known as semantic heterogeneity and are problems of the semantic interoperability.

In this context, is it possible to propose a vertical and horizontal integration intelligent system in order to support all phases of a manufacturing process, overcoming the semantic interoperability obstacles? 


\section{Related Works}

This section presents the main topics contained in related works of the current literature, that are in conformity with the research objective, in order to enlighten the path to delimiting the problem and finding a possible solution, as well. These topics are (i) Vertical and Horizontal Integration in Manufacturing Systems; (ii) Semantic Interoperability Concept; and (iii) Ontology-Driven Interoperability.

\subsection{Vertical and Horizontal Integration in Manufacturing Systems}

The companies must answer quickly to the product and manufacturing changes in order to be in a continuous evolution [3]. Industry 4.0 concepts have been applied to increase the level of horizontal and vertical integration on the manufacturing systems through Information Communication Technology [20].

The horizontal integration is presented by [2] as the cooperation between one company and other related companies. Cooperative and competitive relationships establish an ecosystem where information, finances and materials can move continuously in cooperation. From the perspective of the system, the integration includes the interconnection of the elements of value, such as equipment, people, organizations, processes and products. The composition of the value networks connects and creates values between the elements. Due to the interactive unions between the elements of value, the companies can generate advances and innovations. This creates the opportunity to develop new business' models [21].

The vertical integration is the integration of elements that are important to the company itself, such as the people, equipment and products in a production line or factory. The vertical integration also includes the tasks of integration, such as marketing, sales, services and procurement [22]. A manufacturing system can unite the activities of manufacturing in a value chain through the cyber-physical systems [21]. The vertical integration allows the holistic view of the manufacturing process and makes it react to the customers' needs as fast as possible [23].

\subsection{Semantic Interoperability Concept}

According to [24] the mistakes and miss-interpretations during the steps of design and manufacture correspond to $85 \%$ of the final cost of the products. In order to guarantee the optimization and cost reduction, keeping the same quality, the share of information during the different steps of the development of products and manufacture must be realized in an efficient manner [25].

[26] defines this situation as a semantic interoperability problem, where the meaning associated to the captured information must be shared between the different domains of a system without losing quality (meaning and intent) during the exchange process. The most common method to guarantee the lossless exchange of information during processes has been the definition of common information models [27] [28]. In order to accomplish this goal, the construction of ontologies has shown itself a viable solution on the formalization of these common information models, as well as in the sharing of formal information through the manufacture processes, what also provides the increase of the presence of the knowledge in the application domains [28] [29]. 
[3] presents that even though technical standards such as ISA-95 (IEC/ISSO 62264) provides a very useful reference towards the interoperability as a tool for manufacture, it shows the limitations by the lack of semantic consistency on its operation/implementation. [30] illustrates the problem of misinterpretation between the users of ISA-95, identifying 83 errors in a simple real-world example, and demonstrating how these could be avoided if formal semantic approaches were used. [3] reinforces that representing information in a robust and consistent interpretable manner, in the way that it can be shared with trust, is a substantial problem.

\subsection{Ontology-Driven Interoperability}

The principles and methods for the representation using ontologies were developed in the field of Artificial Intelligence to ease the share of knowledge and reuse among people and application systems [31]. The ontology was developed to provide a semantic that can be processed by machines in information sources that can be communicated through systems and humans [32]. The concept of ontology has its origin in philosophy, where it means a systematic explanation of being [33]. In the last decade, the concept of ontology has show itself more significant for the Intelligent Information Integration, Internet Information Retrieval, Knowledge Management and Semantic Web. The reason for this expansion is the promise to provide a common understanding and sharing inside a specific domain [34]. Nowadays, the ontology is recognized as an important technology to face issues of semantic interoperability [17].

Several research works have been carried out in the field of engineering applying ontologies to solve specific semantic interoperability issues. [35] researched a framework to semantically support the interoperability between design between product design and manufacturing. [36] created information mapping to translate information from the product design to manufacturing. [37] defined a model of manufacturing engineering that can be applied to enable the exchange of information between companies and between multi-disciplinary teams of design and engineering. [38] proposes an ontological model to evaluate the adesion of existing production systems to engineering changes requests or new products in the context of the automobilistic industry. [39] presents a semantic model to support the calculation of energy efficiency indicators in welded-assembly processes.

The combination between Ontology Web Language (OWL) and the Semantic Web Rule Language (SWRL) was employed to solve different issues in representing constraints in formal models. Works such as [40] [41] [42] and [43] explore the combination of OWL and SWRL. Rules in SWRL offer a powerful layer of axioms that cooperate with OWL-based ontologies in order to provide the semantic enrichment.

\section{Discussion}

In order to meet the request of the Industry 4.0 to the connection and integration between processes (vertical) and companies (horizontal), it is necessary, before, to step back once. It is necessary to organize and formalize the information and integrate the internal processes, in the way of assuring the quality and confidence of the information that will be repassed to the partner companies. For this to be possible, the integration could be analysed at principle under the optics of processes and operations, dealing with the 
vertical integration as the layers of systems in each process and the horizontal integration as the continuity of information and knowledge between every parallel process in the manufacturing.

The tools proposed by the literature when applied to other domains of knowledge has shown themselves very effectively. Analysing the problem of the integration of the layers and processes as a problem of semantic interoperability it is possible to verify that, in an integrated manufacturing environment, with the problems of information traffic, the ontologies seems to be an interesting path to the solution.

However, the development process of this system would require the integration of several domains / disciplines of knowledge. Examples are mechanics, electrics and automation that are applied to the machines, chemistry for the processes, materials engineering, production management, business, marketing and many others. This requires a multidisciplinary team to work together upon creating manners of gathering all the information and knowledge involved in the manufacturing process in a single source. One of the obstacles that this platform will have to overcome is how to ease the transdisciplinary interaction among all these areas.

To realize formal modelling in ontology, adequating the variables correctly in every step of the process for them to contribute with a unified common model, has the potential to turn the information accessible to every part of the manufacturing process. Additionally, once the models are organized and structured, a new horizon is open for the application of techniques from semantic interoperability, enabling for example to create formal rules and establishing relationships among these entities in order to aid the decision making and generation of new knowledge.

With the knowledge formalized and accessible to every layer of all the production processes, it would be possible to minimize the errors, integrating the different layers and levels of information, reducing drastically (or even extinguishing) the necessity of the operator in some cases. In this manner it would be possible also to share information with partner companies with trust, enlarging the productivity of the ecosystem as a whole.

Figure 2 presents the possible conceptual model of the integrated manufacturing system with the ontology-based system applied (Detail A of Figure 2). This environment would integrate and reunite the information coming from every system of manufacture aid through the semantic reconciliation technologies (Detail B of Figure 2). This way, beyond promoting the horizontal and vertical integration inside the company, the system would have all the knowledge of the process formalized and unified, improve the decision-making on the level of understanding, and possibly reducing drastically human mistakes on the integration of the systems.

However, it is necessary to emphasize that the application of ontologies to industrial processes are recent and in development. The technologies of semantic interoperability require a specialist for the implementation and are made in manual processes, nonautomatized, making this procedure relatively costly. 


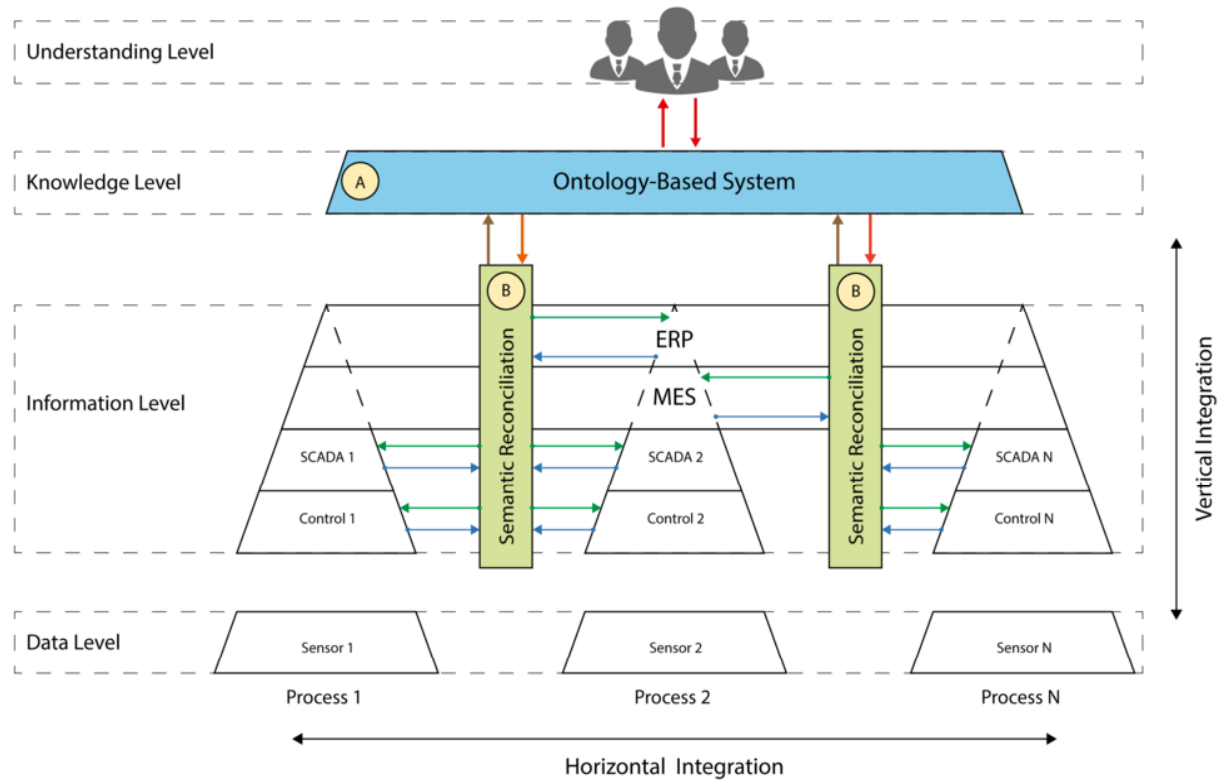

Figure 2. The conceptual solution for the interoperability problem in an Integrated Manufacturing System.

\section{Conclusion}

This article presented research directed to identify the problems on the flow of information in an integrated manufacturing system and possible solutions explored by the literature. This work is pertinent as an initial approach to the problem, showing the direction to be followed in future research. However, many challenges and problems need to be solved with horizontal and vertical integration. The ontologies and semantic interoperability tools have shown as a relevant solution for the problem of information integration to the layers of software and processes.

Additionally, the application of these technologies is not trivial and requires a holistic view of the whole manufacturing system, with specialists dedicated full time for the modelling of the knowledge structure. But, the integration of these processes can reduce drastically the necessity of human interference, increasing the confidence and quality of information, impacting directly on the productivity of the company.

As a future work of this research, it is necessary to carry out a deeper review of the literature through a systematic literature review, in order to define and validate the stateof-art in the related topics. The authors suggested as the main topics to the systematic literature review to explore semantic interoperability subject, integrated manufacturing systems, horizontal and vertical systems integration and other related areas. Additionally, the authors suggest the application of the main concepts identified in the literature review in experimental real cases. 


\section{References}

[1] D. Kindström, C. Kowalkowski, and E. Sandberg, Enabling service innovation: A dynamic capabilities approach, Journal of Business Research, vol. 66, no. 8, pp. 1063-1073, 2013.

[2] N. Chungoora, A.-F. Cutting-Decelle, R. I. M. Young, G. Gunendran, Z. Usman, J. A. Harding, and K. Case, Towards the Ontology-Based Consolidation of Production-Centric Standards, International Journal of Production Research, vol. 51, no. 2, pp. 327-345. 2013.

[3] C. Palmer, Z. Usman, O. Canciglieri Junior, A. Malucelli and R. I. M. Young, Interoperable manufacturing knowledge systems, International Journal of Production Research, vol. 56, no. 8, pp. 2733-2752, 2018.

[4] A. L. Szejka, O. Canciglieri Junior, E. Rocha Loures, H. Panetto, A. Aubry, Proposal of a model-driven ontology for product development process interoperability and information sharing. In: Harik R., Rivest L., Bernard A., Bouras A., Eynard B. (eds.) PLM 2016. Product Lifecycle Management: PLM 2016. Columbia, USA. In: Proceedings of the 13th IFIP International Conference on Product Lifecycle Management (PLM 2016). Columbia, USA, July 11-13,2016. Springer, IFIP and LNCS. Springer, Heidelberg, 2016.

[5] M. Imran and R. I. M. Young, Reference ontologies for interoperability across multiple assembly systems. International Journal of Production Research, vol. 54, no. 18, pp. 1-21, 2016.

[6] N. Chungoora and R. I. M. Young, Semantic Reconciliation Across Design And Manufacturing Knowledge Models: A Logic-Based Approach. Applied Ontology, vol. 6, no. 4, pp. 295 -315, 2011.

[7] M. Nagy and M. Vargas-Vera, Multiagent Ontology Mapping Framework for the Semantic Web. IEEE Transactions on Systems, Man, and Cybernetics - Part A: Systems and Humans, vol. 41, no. 4, pp. 693704, 2011.

[8] A. Gal, A. Anaby-Tavor, A. Trombetta, D. Montesi, A Framework for Modeling and Evaluating Automatic Semantic Reconciliation. International Journal On Very Large Data Bases, vol. 14, no. 1, pp 50-67, 2005.

[9] T. R. Gruber, A Translation Approach To Portable Ontology Specification, Knowledge Acquisition, vol. 5, no. 2, pp. 199-220, 1993.

[10] D. Fensel, Ontologies: A Silver Bullet For Knowledge Management And Electronic Commerce, Second Edition, Springer, 2004.

[11] Engineous, Engineous Int. Symp, The workshop, Novi, Mi, October 10-12, 2005

[12] K.-Y. Kim, S. Chin, O. Kwon, R. D. Ellis. Ontology-Based Modeling and Integration of Morphological Characteristics of Assembly Joints for Network-Based Collaborative Assembly Design, Artificial Intelligence For Engineering Design, Analysis and Manufacturing, vol. 23, no. 1, pp. 71-88, 2009.

[13] W. Zhao and J. K. Liu, OWL/SWRL Representation Methodology for Express-Driven Product Information Model Part I. Implementation Methodology, Computers In Industry, vol. 59, pp. 580-589, 2008 .

[14] Y. Biletskiy, O. Vorochek and A. Medovoy, Building Ontologies for Interoperability among Learning Objects and Learners, Lecture Notes In Computer Science, vol. 3029, pp. 977-986, 2004.

[15] R. Mizoguchi, Tutorial On Ontological Engineering Part 1: Introduction to Ontological Engineering, New Generation Computing, vol 21, no. 4, pp. 365-384, 2003.

[16] R. Mizoguchi, Tutorial on Ontological Engineering Part 2: Ontology Development Tools and Languages. New Generation Computing, vol. 22, no. 2, pp. 61-96, 2004.

[17] R. Mizoguchi, Tutorial on Ontological: Engineering Part 3 Advanced Course of Ontological Engineering. New Generation Computing, vol. 22, no. 2, pp. 198-220, 2004.

[18] R. L. Ackoff, From Data to Wisdom, Journal of Applied Systems Analysis, vol. 16, pp. 3-9, 1989.

[19] Hervé Panetto, Milan Zdravković, Ricardo Jardim - Goncalves, David Romero, J. Cecil, et al.. New Perspectives for the Future Interoperable Enterprise Systems. Computers in Industry, Elsevier, 2016, Special Issue: "Future Perspectives on Next Generation Enterprise Information Systems: Emerging Domains and Application Environments", 79, pp. 47-63.10.1016/j.compind.2015.08.001.hal-01142747

[20] C. M. Tung, Vertical integration for smart manufacturing-The dynamic capability perspective, Journal of Advances in Technology and Engineering Research, vol. 4, no. 2, p 70-78, 2018.

[21] T. Stock and G. Seliger, Opportunities of sustainable manufacturing in industry 4.0, Procedia CIRP, vol. 40, pp. 536-541, 2016

[22] M. Marques, C. Agostinho, G. Zacharewicz and R. Jardim-Gonçalves, Decentralized decision support for intelligent manufacturing in Industry 4.0, Journal of Ambient Intelligence and Smart Environments, vol. 9, no. 3, pp. 299-313, 2017.

[23] R. Burke, A. Mussomeli, S. Laaper, M. Hartigan, and B. Sniderman, The smart factory: Responsive, adaptive, connected manufacturing, Deloitte Insights, vol. 31, no. 6, pp. 50-60, 2017. 
[24] H. Rozenfeld, F. A. Forcellini, D. C. Amaral, J. C. Toledo, S. L. Silva, D. H. Alliprandini and R. K. Scalice. Gestão de Desenvolvimento de Produtos: Uma Referência Para a Melhoria do Processo, São Paulo: Saraiva, 2006.

[25] M. B. Canciglieri, A. L. Szejka, O. Canciglieri Junior and L. Yoshida, Current Issues in Multiple Domain Semantic Reconciliation for Ontology-Driven Interoperability in Product Design and Manufacture. In: Chiabert P., Bouras A., Noël F., Ríos J. (eds) Product Lifecycle Management to Support Industry 4.0. PLM 2018. IFIP Advances in Information and Communication Technology, vol 540. Springer, Cham, 2018.

[26] N. Chungoora, A Framework to Support Semantic Interoperability in Product Design and Manufacture, $\mathrm{PhD}$ Thesis, Loughborough University, Loughborough, Uk., 2010.

[27] O. Canciglieri Junior and R. I. M. Young, Information Mapping Across Injection Moulding Design and Manufacture Domains, International Journal Of Production Research, vol. 41, no. 7, pp. 4437-4462, 2010.

[28] A. Yang, B. Braunschweig, E. S. Fraga, Z. Guessoum, W. Marquardt, O. Nadjemi, D. Paen, D. Piñol, P. Roux, S. Sama, M. Serra, I. Stalker, A Multi-Agent System To Facilitate Component-Based Process Modeling and Design, Computers \& Chemical Engineering, vol. 32, no. 10, pp. 2290-2305, 2008.

[29] A. Gomez-Perez, O. Corcho and M. Fernandez Lopez, Ontological Engineering: With Examples from the Areas of Knowledge Management, E-Commerce And The Semantic Web, Madrid: Springer, 2004.

[30] N. Hastilow, Manufacturing Systems Interoperability in Dynamic Change Environments, Thesis (PhD), Loughborough University, Loughborough, Uk., 2013.

[31] A. Malucelli, Ontology-based Services for Agents Interoperability, Thesis (PhD), University of Porto, Porto, Portugal, 2006.

[32] M. Ehrig and Y. Sure, Ontology mapping - An integrated approach. In: The Semantic Web: Research and Applications. Bussler C.J., Davies, J., Fensel, D., Studer, R. (eds.) ESWS2004. LNCS, vol. 3053, pp. 76-91, Springer, Heidelberg, 2004.

[33] O. Corcho, M. Fernández-López and A. Gómez-Pérez. Methodologies, tools and languages for building ontologies. Where is their meeting point? Data \& Knowledge Engineering, vol. 46, n. 1, pp. 41-64, 2003.

[34] M. Imran and R. I. M. Young, Reference ontologies for interoperability across multiple assembly systems, International Journal of Production Research, vol. 54, n. 18, pp. 1-21, 2016.

[35] N. Chungoora, O. Canciglieri Junior and R. I. M. Young, Towards expressive ontology-based approaches to manufacturing knowledge representation and sharing, International Journal of Computer Integrated Manufacturing, vol. 23, n. 12, pp. 1059-1070, 2010.

[36] O. Canciglieri Junior and R. I. M. Young, Information mapping across injection moulding design and manufacture domains, International Journal of Production Research, vol. 41, no. 7, pp. 4437-4462, 2010.

[37] H. K. Lin, and J. A. Harding, A manufacturing engineering ontology model on the semantic web for inter-enterprise collaboration. Computers in Industry, vol. 58, no. 5, pp. 428-437, 2007.

[38] Jaqueline Sebastiany Iaksch, Milton Borsato, Method for digital evaluation of existing production systems adequacy to changes in product engineering in the context of the automotive industry, Advanced Engineering Informatics, Volume 42, 2019, 100942, ISSN 1474-0346, https://doi.org/10.1016/j.aei.2019.100942.

[39] Milton Borsato, An energy efficiency focused semantic information model for manufactured assemblies, Journal of Cleaner Production, Volume 140, Part 3, 2017, Pages 1626-1643, ISSN 0959-6526, https://doi.org/10.1016/j.jclepro.2016.09.185.

[40] K.-Y. Kim, D. G. Manley and H. Yang, Ontology-based assembly design and information sharing for collaborative product development, Computer-Aided Design, vol. 38, no. 12, pp. 1233-1250, 2006.

[41] M. Rabe and P. Gocev, Semantic web framework for the rule-based generation of knowledge and simulation of manufacturing systems. In: Mertins, K., Ruggaber, R., Popplewell, K. and Xu, X., eds. Enterprise interoperability III: new challenges and industrial approaches, London, UK: Springer-Verlag, 2008, pp. 397-409.

[42] X. Chang, A. Sahin and J. Terpenny, An ontology-based support for product conceptual design, Robotics and Computer-Integrated Manufacturing, vol. 24 no. 6, pp. 755-762, 2008.

[43] S. Wei, M. Qin-Yi, G. Tian-Yi, An ontology-based manufacturing design system. Information Technology Journal, vol. 8, no. 5, pp. 643-656, 2009. 